\title{
Análise da Evolução da Ocupação Urbana e dos Aspectos Socioeconômicos na Bacia Hidrográfica do João Mendes, Niterói - RJ: contribuições à gestão ambiental
}

\author{
Analysis of the Evolution of Urban Occupation and Socioeconomic Aspects in the \\ João Mendes Basin, Niterói - RJ: contributions to environmental management
}

\author{
Análisis de la Evolución de la Ocupación Urbana y de los Aspectos \\ Socioeconómicos en Cuenca João Mendes, Niterói - RJ: contribuciones a la gestión \\ ambiental
}

Thiago dos Santos Leal ${ }^{1}$

Otávio Miguez da Rocha Leão

\begin{abstract}
RESUMO: As bacias hidrográficas em áreas urbanas têm sofrido várias intervenções estruturais negativas, o que gera mudanças na dinâmica hidrológica. Assim, o presente estudo objetiva identificar a evolução urbana entre 1976 e 2014 na bacia hidrográfica do Rio João Mendes e avaliar as áreas mais vulneráveis na bacia, no que tange aos aspectos socioeconômicos, as quais necessitam de ações prioritárias, seja de medidas estruturais e/ou não estruturais, pelo poder público. Para tanto foram realizados trabalhos de campo, geração do mapa de classificação das áreas edificadas e da cobertura vegetal e análise socioeconômica baseada nas faixas de rendimentos em número de salários mínimos por setor censitário (censo 2010) e na porcentagem de domicílios com esgotamento por setor censitário com base no banco de dados disponibilizados pelo IBGE (2010). Os resultados demonstram um aumento de aproximadamente $85 \%$ de ocupação urbana (de $14 \%$ para $26,64 \%$ ) na bacia entre os anos de 1976 e 2014. É importante que o poder público intensifique investimentos nos setores censitários que apresentaram as menores porcentagens de domicílios com esgotamento variando entre 0 e $25 \%$.
\end{abstract}

PALAVRAS-CHAVE: Bacias hidrográficas. Áreas vulneráveis. Aspectos socioeconômicos.

\begin{abstract}
The river basins in urban areas have undergone several negative structural interventions, which have generated changes in the hydrological dynamics. Thus, the present study aims to identify the urban evolution between 1976 and 2014 in the João Mendes river basin and to evaluate the most vulnerable areas in the basin in terms of socioeconomic aspects, which require priority actions, either structural and/or nonstructural measures, by the public power. For that, fieldwork was carried out, generation of the classification map of built-up areas and vegetation cover, and socioeconomic analysis based on income ranges in number of minimum wages by census sector

\footnotetext{
${ }^{1}$ Programa de Pós-Graduação em Geografia na UFRJ. Av. Athos da Silveira Ramos, 274 - Cidade Universitária - Ilha do Fundão, Rio de Janeiro, RJ, 21941-916. thiagolealgeo@gmail.com.

${ }^{2}$ Faculdade de Formação de Professores da Universidade do Estado do Rio de Janeiro (UERJ). R. Francisco Portela, 1470 - Patronato, São Gonçalo - RJ, 24435-005. orochaleao@hotmail.com.
} 
(2010 census) and percentage of households with exhaustion by sector census based on the database provided by IBGE (2010). The results showed that there was an increase of approximately $85 \%$ of urban occupation (from 14\% to 26.64\%) in the basin between 1976 and 2014. It is important that the public power intensifies investments in the census tracts that presented the lowest percentages of households with exhaustion ranging from 0 to $25 \%$.

KEY WORDS: Watersheds. Vulnerable areas. Socioeconomic aspects.

RESUMEN: Las cuencas hidrográficas en áreas urbanas han sufrido varias intervenciones estructurales negativas lo que ha generado cambios en la dinámica hidrológica. Así el presente estudio objetiva identificar la evolución urbana entre 1976 y 2014 en la cuenca hidrográfica del Río João Mendes y evaluar las áreas más vulnerables en la cuenca en lo que se refiere a aspectos socioeconómicos, las cuales necesitan acciones prioritarias, sea de medidas estructurales y / o no estructurales por el poder público. Para ello se realizaron trabajos de campo, la generación del mapa de clasificación de las áreas edificadas y de la cobertura vegetal y análisis socioeconómico basado en las franjas de ingresos en número de salarios mínimos por sector censal (censo 2010) y en el porcentaje de hogares con agotamiento por sector de acuerdo con la base de datos proporcionada por el IBGE (2010). Los resultados mostraron que hubo un aumento de aproximadamente el $85 \%$ de ocupación urbana (del 14\% al 26,64\%) en la cuenca entre los años 1976 y 2014. Es importante que el poder público intensifique inversiones en los sectores censales que presentaron los menores porcentajes de hogares con agotamiento que oscilan entre el 0 y el $25 \%$.

PALABRAS-CLAVE: Cuencas hidrográficas. Áreas vulnerables. Aspectos socioeconomicos.

\section{INTRODUÇÃO}

As bacias hidrográficas em áreas urbanas têm sido substancialmente afetadas por vários fatores como a redução de áreas verdes, uso e ocupação irregular nas encostas e nas planícies de curso d'água, a impermeabilização do solo, a disposição indevida dos resíduos sólidos, e as alterações nos aspectos estruturais e formais da bacia e dos canais de drenagem (como vazão, canalização de canais, capeamentos e mudança de percurso). Tais fatores alteram a dinâmica hidrológica das bacias dificultando a infiltração e percolação da água no solo e promovendo um maior escoamento superficial, principalmente da água pluvial, promovendo não raras vezes o fenômeno da inundação.

É interessante notar que qualquer alteração ambiental sofrida em uma dada porção da bacia de drenagem pode afetar outras áreas situadas à jusante. Segundo Coelho Netto (2005), isto significa que os efeitos hidrológicos e geomorfológicos de processos naturais ou antrópicos refletem num determinado ponto de saída de uma bacia de drenagem, podendo propagar-se a jusante por meio de bacias de drenagem adjacentes. Tais aspectos devem ser levados em consideração no planejamento e na gestão das formas de intervenção humana, mesmo que o interesse do planejador/gestor recaia sobre uma área restrita da bacia de drenagem. 
Destarte, analisar as forças promotoras da evolução urbana em uma determinada bacia, bem como as formas de ocupação, é fundamental, uma vez que algumas atividades humanas aumentam a ocorrência de certos impactos ambientais, dando origem ao que Vinchon et al. (2011) denominaram de desastres socionaturais. Portanto, é necessária a articulação da dinâmica hidrológica e das diferentes formas de uso e ocupação humana, unindo preceitos e ferramentas de redução de risco socionatural à gestão integral de desastres, contemplando mudanças estruturais que podem ocorrer e que estão enquadradas em políticas de desenvolvimento humano.

Assim este trabalho objetivou avaliar o crescimento urbano ocorrido na bacia hidrográfica do rio João Mendes (localizado no município de Niterói - RJ) entre os anos de 1976 e 2014, e analisar os indicadores socioeconômicos, focando a faixa de rendimentos em salários mínimos e da porcentagem de domicílios com esgotamento por setor censitário, estabelecendo ações eficazes para melhoria contínua da gestão ambiental.

\section{METODOLOGIA}

\section{Localização e Caracterização da Área de Estudo}

A bacia do Rio João Mendes está localizada na região metropolitana do Rio de Janeiro, no município de Niterói, conforme pode ser visto na figura 1. Segundo Leal e Rocha-Leão (2018) a bacia apresenta 14,3 quilômetros quadrados de área, compreendendo mais de $10 \%$ da área total do município. Possui, em termos hidrológicos, destaque em função de ser a bacia de maior importância na contribuição para Laguna de Itaipu. 
Figura 1 - Localização da bacia do Rio João Mendes

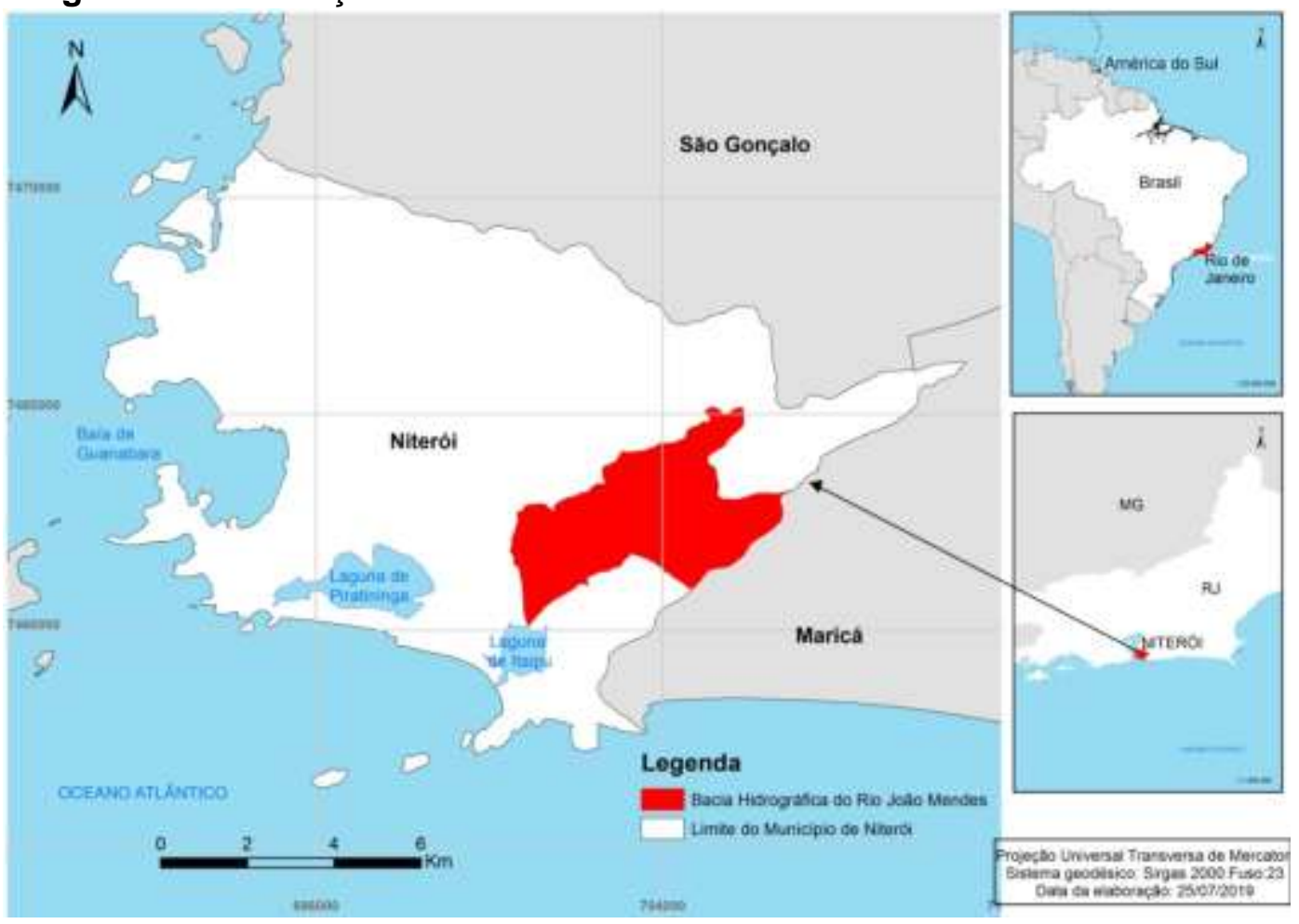

Fonte: Leal e Rocha-Leão (2018).

\section{MATERIAIS E MÉTODOS}

A metodologia do presente estudo se baseou em três pilares: extensa revisão de literatura para a fundamentação teórica, trabalho de campo e geração do mapa de expansão urbana dos anos de 1976 e 2014 e análise socioeconômica baseada nas faixas de rendimentos em número de salários mínimos por setor censitário (censo 2010), e também na porcentagem de domicílios com esgotamento por setor censitário com base nos arquivos vetoriais (shapefiles) e banco de dados disponibilizados pelo IBGE referente ao censo de 2010. Desta forma, com o uso do software Arcgis $10.5 \AA$ por meio da ferramenta "join" de acordo com o campo do código censitário foi associada a planilha ao shapefile dos setores censitários. Os trabalhos de campo foram realizados em duas datas, a saber: 17 de junho de 2017 e 14 de novembro de 2017, com levantamentos de pontos na bacia conforme figura 2.

No primeiro campo (17/06/2017) foram avaliados os pontos 1 e 2 , tendo como objetivo observar as características físico-naturais da área da bacia que está mais preservada, ou seja, que não sofreu ocupação urbana de forma intensa.

No segundo campo (14/11/2017) foram avaliados 4 pontos no médio e baixo curso (3, 4,5 e 6) do rio onde há intervenções significativas de obras de engenharia, ocupação 
irregular nas margens e sobre o rio, o que altera sensivelmente os aspectos quantitativos e qualitativos do corpo hídrico.

Figura 2 - Localização dos pontos avaliados na bacia do Rio João Mendes

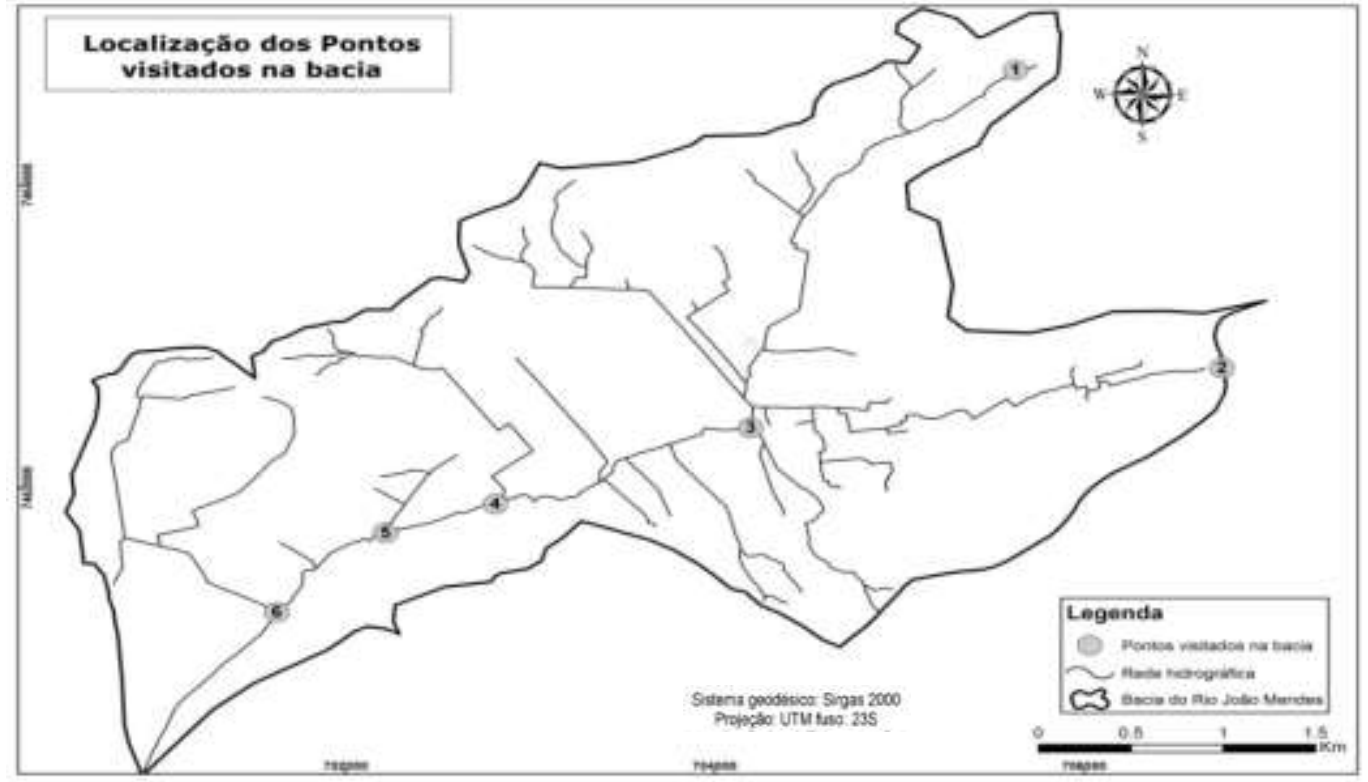

Fonte: Organizado pelos autores.

Para geração do mapa de expansão da ocupação urbana na bacia nos anos de 1976 e 2014 utilizou-se a classificação supervisionada, a partir do software Arcgis $10.5 \AA$, com o classificador de Máxima Verossimilhança (MAXVER), "pixel a pixel", num total de 136 amostras, sendo 74 amostras para área urbana edificada e 62 amostras para cobertura vegetal. Segundo Rosa (2009) a classificação de imagens refere-se à utilização de computadores para a interpretação de imagens de sensoriamento remoto, quando são atribuídos significados aos pixels, em função das características numéricas.

\section{RESULTADOS E DISCUSSÕES}

\section{Evolução da Ocupação Urbana na Bacia nos Anos de 1976 e 2014}

Segundo Galvão (2014) as áreas loteadas na Região Oceânica permaneceram, na sua grande maioria desocupadas até 1970, quando foi construída a Ponte Presidente Costa e Silva (Rio - Niterói).

A construção da Ponte Rio-Niterói acelerou o processo de urbanização do município de Niterói e, consequentemente, da própria Região Oceânica, onde se localiza o Rio João Mendes. Com isso os acessos às áreas litorâneas foram melhorados com investimentos na 
Estrada Velha de Itaipu e a construção do túnel Icaraí-São Francisco. Com base no mapa da evolução urbana foi possível perceber o crescimento das áreas impermeabilizadas na bacia, conforme indicam as figuras 3,4 e 5 .

Figura 3 - Ocupação Urbana na bacia do Rio João Mendes em 1976

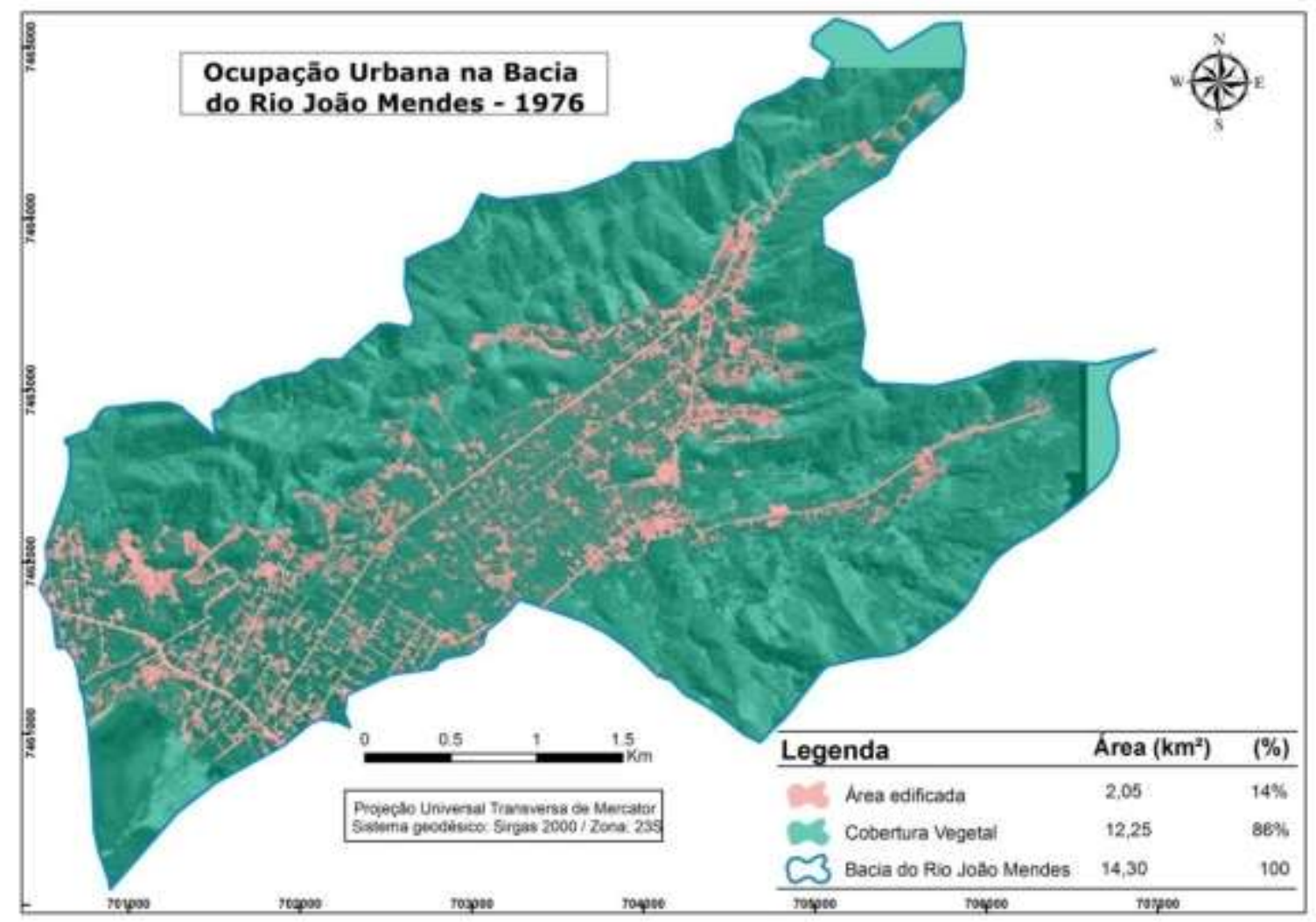

Fonte: Leal (2018).

Segundo a Prefeitura Municipal de Niterói (2002) outro fator a ser levado em consideração no início dos anos de 1980 foi o papel da Avenida Ewerton Xavier (antiga Avenida Central) que, ligando o bairro de Itaipu à Rodovia Amaral Peixoto (via de acesso importante à Região dos Lagos), também colaborou para a expansão urbana e estimulou o crescimento de bairros como Itaipu e Maravista. As residências, outrora frequentadas nos finais de semana, agora passam a ser de moradias permanentes.

A organização do espaço do município de Niterói, e principalmente de sua Região Oceânica, tem grande influência do aumento de moradias tanto regulares quanto irregulares, o que aumenta a aglomeração urbana. Este aumento levou à alteração da superfície topográfica influenciando na dinâmica da água na bacia.

O escoamento superficial pode sofrer influência de uma série de fatores, dentre eles o uso e a ocupação do solo. Um alto grau de compactação do solo ou a falta de cobertura vegetal propiciará uma maior taxa de escoamento. Segundo Maus, Righes e Buriol (2007), tanto em áreas urbanas como em rurais, as ações antrópicas no uso e ocupação do solo 
também apresentam interferência direta na quantidade do escoamento, podendo alterar as vazões mínimas e máximas dos mananciais.

Figura 4 - Ocupação urbana na bacia do Rio João Mendes em 2014

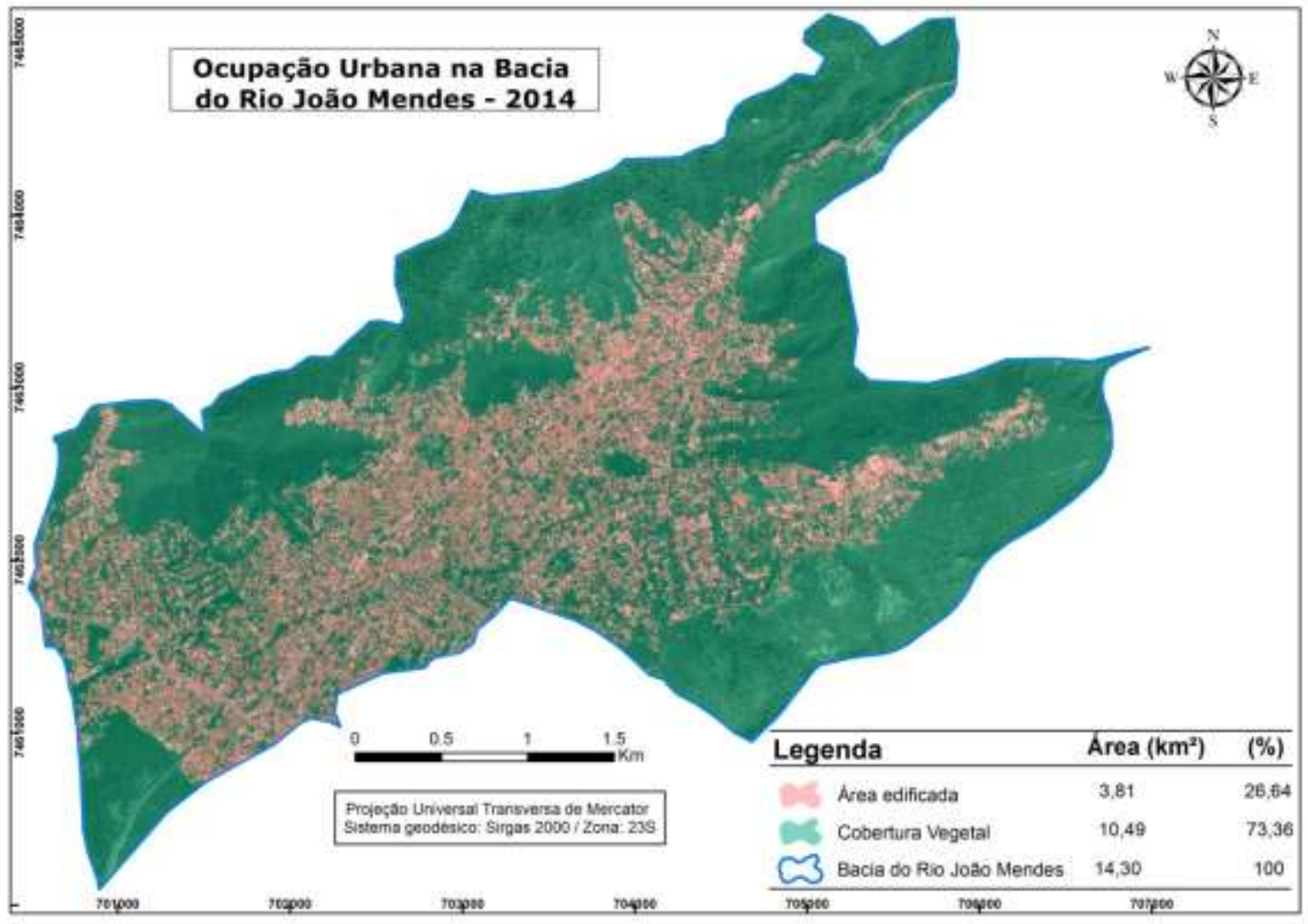

Fonte: Leal; Rocha-Leão (2018).

Figura 5 - Evolução da ocupação urbana em porcentagem em 1976 e 2014

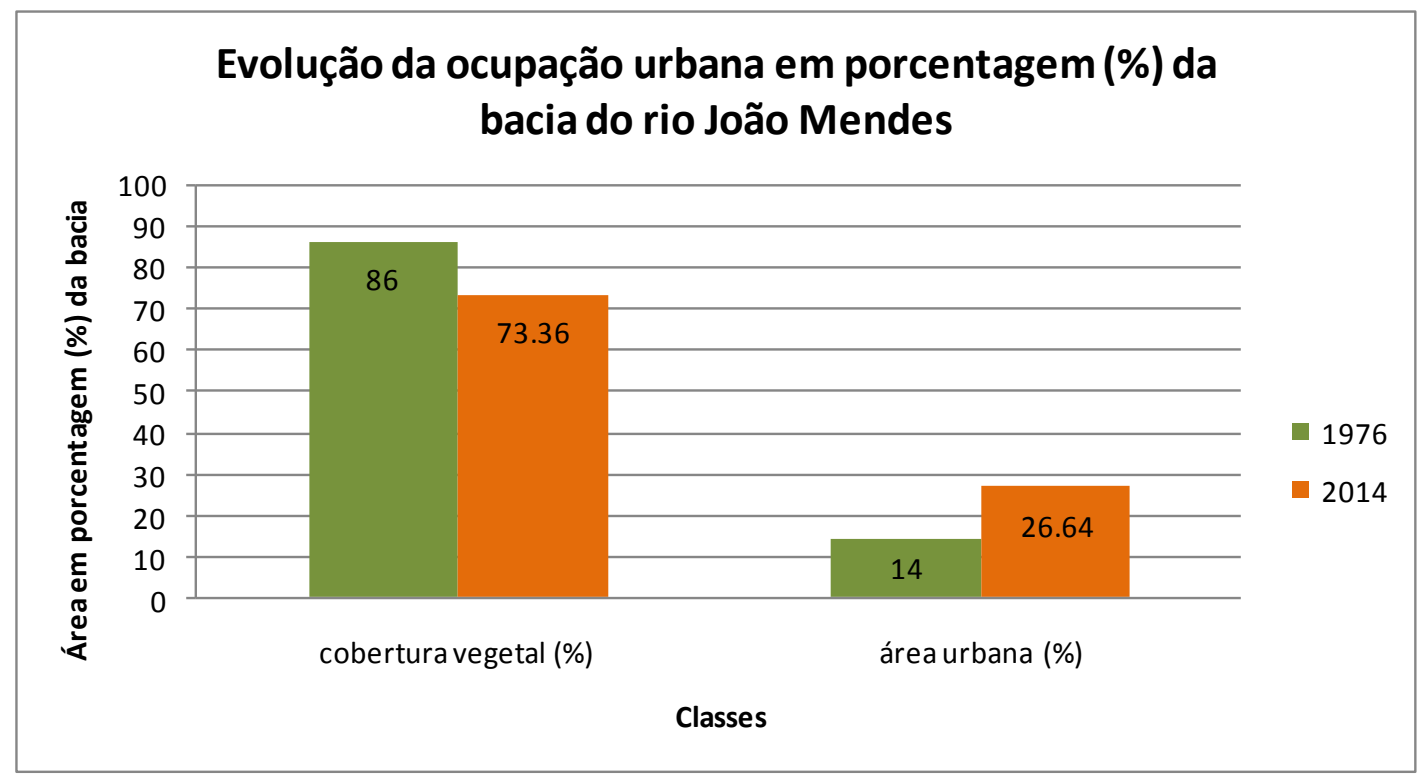

Fonte: Leal (2018). 
Conforme pode ser notado nas figuras 3 e 4, houve um aumento de aproximadamente 85\% de ocupação urbana (de 14\% para 26,64 \%) na bacia entre os anos de 1976 e 2014. Cabe esclarecer que este crescimento pode ser ainda maior uma vez que a fotografia aérea de 1976 possuía apenas uma banda espectral (Pancromática) e apresentava resolução espacial de 100 centímetros, o que fez com que parte da classificação fosse refinada manualmente, e já para fotografia aérea de 2014 foram usadas 3 bandas ( $R, G$ e B) com resolução espacial de 10 centímetros, o que implica uma maior precisão nos resultados finais.

Quando comparamos as áreas de cabeceira da bacia com as áreas de planície a partir das figuras 3 e 4, nota-se que há um maior crescimento urbano na área de planície, exatamente onde ocorre o fenômeno da inundação.

Já nas vertentes mais altas da bacia há um alto gradiente topográfico, atrelado a presença de cursos d'água encaixados e vegetação mais preservada, o que diminui a propensão à inundação. Na avaliação de campo (nos pontos 1 e 2, conforme indicado na figura 2) foi possível perceber nessas áreas bom estado de preservação (figura 6 item $A$ e B) com floresta de Mata Atlântica em estádio secundário médio e avançado, com presença de vegetação de sub-bosque exuberante, sem lixo no entorno e sem ocupação num raio de 50 metros das nascentes, respeitando assim a área de preservação permanente conforme lei federal №12651 (BRASIL, 2012).

Figura 6 - Áreas de cabeceira da bacia. Foto A representa a nascente e a foto B mostra a nascente do principal afluente Rio João Mendes

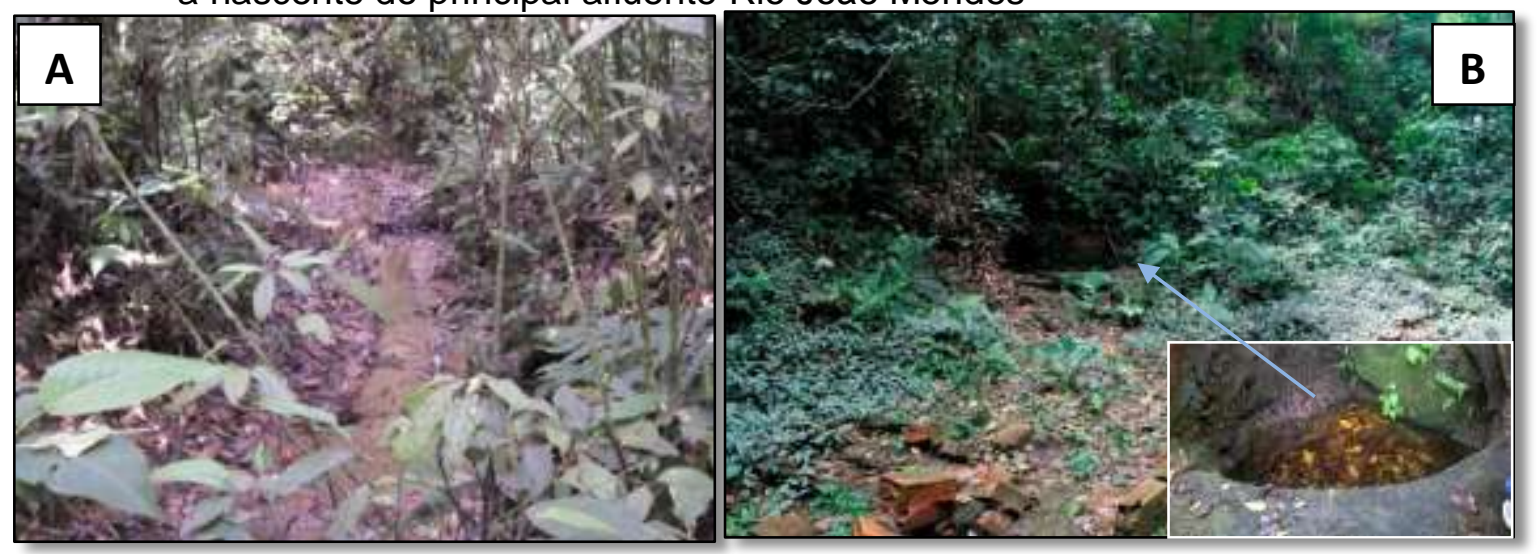

Fonte: Leal (2018).

Cabe ressaltar que na figura 6 item B é possível perceber alguns tijolos relacionados a uma antiga construção que foi demolida próximo ao principal afluente do Rio João Mendes, no entanto atualmente não há moradores e nem construções próximas à área.

Como pode ser percebido na figura 6 itens $A$ e $B$, há cobertura vegetal nas nascentes. Segundo Guerra e Cunha (1994), a cobertura vegetal além de influenciar na interceptação 
das águas da chuva, atua também, de forma direta, na produção de matéria orgânica que, por sua vez, atua na agregação das partículas constituintes do solo.

Segundo o Secretariat of the Convention on Biological Diversity (2012) os espaços urbanos com 50 a $90 \%$ de superfície impermeável podem perder de 40 a $83 \%$ da água da chuva para o escoamento superficial, ao passo que áreas com vegetação perdem por volta de $13 \%$ da água da chuva em eventos semelhantes de precipitação, sem contar o papel fundamental também como sistema de biofiltração e diminuição de poluentes nos cursos d'água.

Desta forma o processo de urbanização na bacia hidrográfica gera impermeabilização, o que diminui a infiltração da água no solo e antecipa os picos de vazão no tempo, tendo em vista que a construção de galerias de águas pluviais e a canalização dos cursos d'água na bacia tornam os escoamentos superficiais mais rápidos. Com a retirada da cobertura vegetal ocorre também redução da evapotranspiração, visto que a área urbana não armazena água como a cobertura vegetal.

\section{Faixas de Rendimentos em Salários Mínimos por Setor Censitário}

A bacia hidrográfica do Rio João Mendes é caracterizada por espaços urbanos com indicadores socioeconômicos extremamente desiguais. Há uma acentuada desigualdade social e segregação socioespacial no contexto da bacia, cujo reflexo são habitações de baixo padrão construtivo, pautados pelo esforço da autoconstrução e da prática de mutirões.

$\mathrm{Na}$ mesma bacia é possível perceber setores censitários cujas faixas de rendimentos em número de salários mínimos estão entre 0 a 2, com proximidade de setores censitários cuja faixa de rendimento em número de salários mínimos por setor censitário está entre $10 \mathrm{e}$ 20, conforme indicado na figura 7 .

Há uma parcela significativa de edificações nos setores censitários, tanto de maior renda quanto de menor renda, nas margens dos cursos d'água e, portanto, inseridas em áreas de alta suscetibilidade à inundação. Construir em áreas de grande vulnerabilidade não está restrito exclusivamente aos pobres. O mesmo é reafirmado por Saito (2011) o qual defende a noção de que a vulnerabilidade não é um sinônimo da pobreza.

A pobreza e a vulnerabilidade são condições sociais que se reforçam mutuamente. Segundo Freitas (2016), parcela significativa da população é vulnerável, apesar de não ser considerada pobre de acordo com os critérios estabelecidos pela linha da pobreza.

Assim se percebe que as políticas públicas de reassentamento de famílias em situação de risco devem ocorrer de forma prioritária nas áreas onde o rendimento médio de salários mínimos por setores censitários são menores. Neste contexto é importante também serem observadas as exceções, pois algumas casas na margem do rio que estão inseridas 
no setor censitário de 4 a 10 salários mínimos não correspondem a esta faixa salarial, como pode ser observado nas figuras 8 e 9 .

Figura 7 - Mapa socioeconômico da bacia do Rio João Mendes

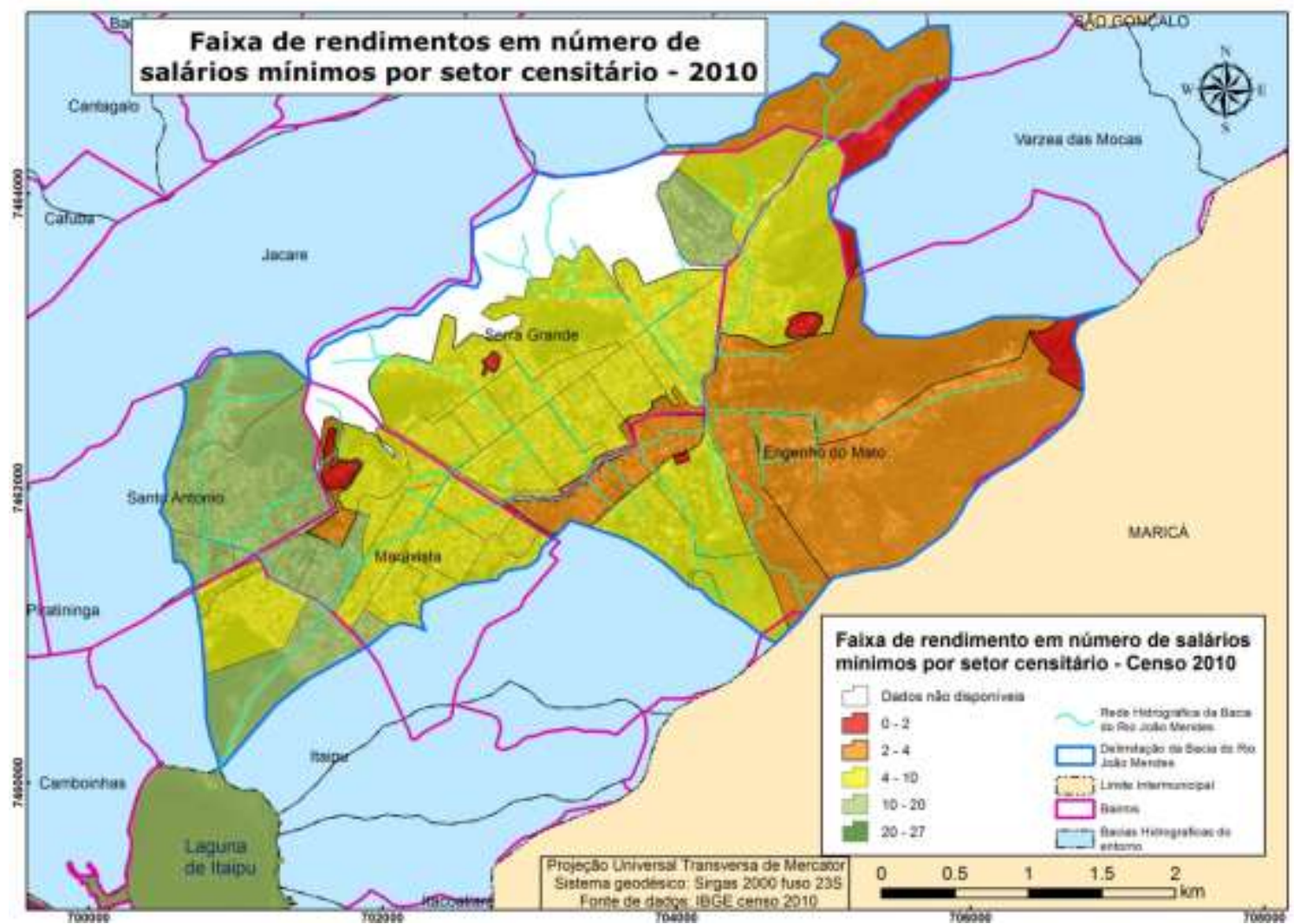

Fonte: Adaptado de Leal (2018).

Figura 8 - Valor da casa a venda sobre o rio João Mendes no setor censitário de 4 a 10 salários mínimos

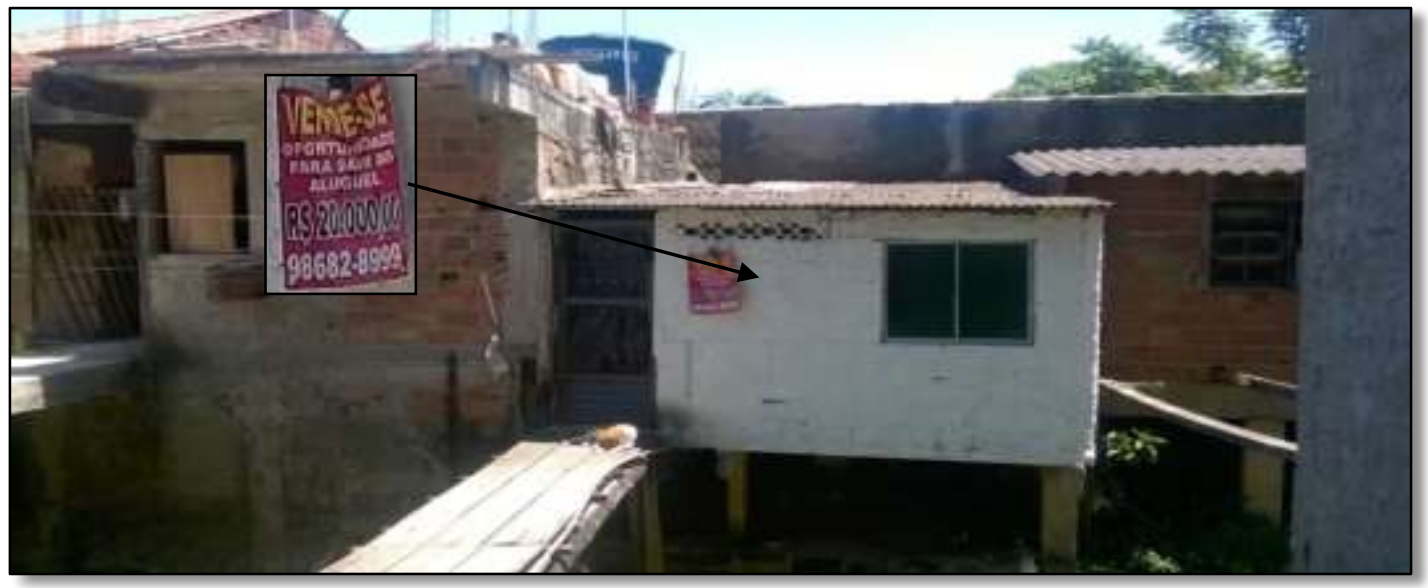

Fonte: Leal (2018).

Na figura 8 pode ser observado no cartaz vermelho, pregado na parte frontal da casa, que a casa está à venda por $R \$ 20.000,00$ (vinte mil reais). Já na figura 9 pode ser notada outra casa construída sobre o rio com comprimento ocupando de uma margem a outra. 
Figura 9 - Casa construída sobre o rio João Mendes inserida no setor censitário de 4 a 10 salários mínimos, ocupando de uma margem a outra



Fonte: Leal (2018).

Isso demonstra a vulnerabilidade social nesta área e a necessidade de ações prioritárias de fiscalização e reassentamento. Se por um lado há a necessidade de ações fiscalizadoras com maior frequência nas margens do rio pelas autoridades competentes, por outro é necessária a mitigação do problema já deflagrado que é a ocupação em área de risco, o que poderia ser solucionado com novas construções multifamiliares na bacia.

\section{Porcentagem de domicílios com esgotamento por setor censitário}

O esgotamento sanitário é outro importante indicador para o entendimento da dinâmica hidrológica da bacia hidrográfica, pois interfere tanto na quantidade quanto na qualidade da água na rede de drenagem da bacia.

Esgotamento sanitário é todo despejo líquido proveniente de esgotos domésticos e industriais, água de infiltração e contribuição parasitária. O esgoto doméstico é gerado a partir da água de abastecimento, que no caso de Niterói advém da água bruta retirada próxima à confluência dos rios Guapiaçu e Macacu, no município de Guapimirim - RJ.

O sistema de abastecimento de água do município de Niterói é composto de duas partes que operam integradas. A primeira, de responsabilidade da Companhia Estadual de Águas e Esgotos (CEDAE), compreende um sistema composto de captação em manancial superficial, canal adutor de água bruta, elevação e uma unidade de tratamento e de parte de adução de água tratada. Este sistema é denominado Imunana-Laranjal. Já a segunda, de responsabilidade da concessionária (no caso Grupo Águas do Brasil), abrange adução de água tratada, reservação e redes de distribuição (NITERÓI, 2015).

O Ranking de Saneamento com os melhores e piores índices de saneamento (água e esgoto) nos 100 maiores municípios do Brasil foi divulgado em abril de 2018 pelo Instituto 
Trata Brasil em parceria com a GO Associados, conforme pode ser visto na figura 10. Neste ranking, Niterói aparece em 19² no Brasil.

Figura 10 - Ranking de Saneamento 2018

\begin{tabular}{|c|c|c|c|c|c|c|c|c|c|c|c|c|}
\hline$\frac{\frac{0}{2}}{\frac{\hat{N}}{E}}$ & 5 & 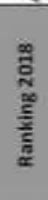 & 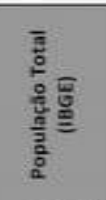 & 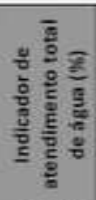 & 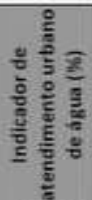 & 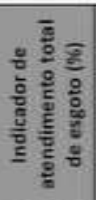 & 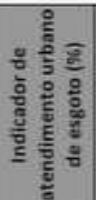 & 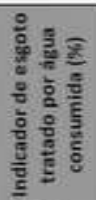 & 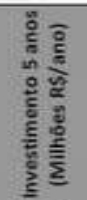 & 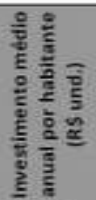 & 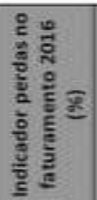 & 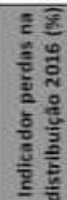 \\
\hline Franca & $S P$ & 1 & 344.704 & 99,97 & 100,00 & 99,62 & 100,00 & 98,03 & 325,99 & 189,14 & 12,73 & 25,85 \\
\hline Cascavel & PR & 2 & 316.226 & 99,99 & 100,00 & 100,00 & 100,00 & 94,57 & 175,92 & 111,26 & 20,66 & 33,53 \\
\hline Uberlândia & MG & 3 & 669.672 & 100,00 & 100,00 & 97,23 & $100, \infty 0$ & 76,44 & 266,05 & 79,46 & 21,57 & 25,20 \\
\hline Vitória da Conquista & BA. & 4 & 346.069 & 100,00 & 100,00 & 83,56 & 93,33 & 86,36 & 131,36 & 75,92 & $-10,58$ & 19,76 \\
\hline Maringá & PR & 5 & 403.063 & 99,99 & 100,00 & 99,99 & 99,99 & 99,08 & 167,95 & 83,34 & 12,20 & 24,75 \\
\hline Limeira & SP & 6 & 298.701 & 97,02 & 100,00 & 97,02 & 100,00 & 100,00 & 82,07 & 54,95 & 10,89 & 1557 \\
\hline Săo José dos Campos. & SP & 7 & 695.992 & 100,00 & 100,00 & 97,33 & 99,35 & 92,20 & 380,51 & 109,34 & 26,56 & 35,51 \\
\hline Taubaté & $S P$ & 8 & 305.174 & 100,00 & 100,00 & 97,03 & 99,17 & 91,11 & 62,53 & 40,98 & 25,52 & 35,96 \\
\hline Säo josé do Rio Preto & SP & 9 & 446.649 & 93,93 & 100,00 & 93,93 & 100,00 & 87,57 & 186,41 & 83,47 & 23,92 & 32,00 \\
\hline Uberaba & MG & 10 & 325.279 & 99,80 & 100,00 & 98,50 & 99,50 & 60,79 & 136,78 & 84,10 & 24,07 & 30,33 \\
\hline Campina Grande & PB & 11 & 407.754 & 99,98 & 100,00 & 89,51 & 93,90 & 99,89 & 23,88 & 11,71 & $-1,89$ & 24,53 \\
\hline Santos & SP & 12 & 434.359 & 99,99 & 100,00 & 99,88 & 99,95 & 97,63 & 108,45 & 49,93 & 18,73 & 17,25 \\
\hline Londrina & PR & 13 & 553.393 & 99,99 & 100,00 & 99,99 & 99,99 & 89,23 & 296,32 & 107,09 & 39,59 & 34,90 \\
\hline Ponta Grossa & $P R$ & 14 & 341.130 & 99,99 & 100,00 & 99,99 & 99,99 & 86,71 & 109,16 & 64,00 & 23,78 & 40,29 \\
\hline Petrolina & $P E$ & 15 & 337.683 & 100,00 & 100,00 & 71,73 & 96,19 & 67,81 & 159,93 & 94,72 & 30,40 & 39,97 \\
\hline Piracicaba & $S P$ & 16 & 394.419 & 100,00 & 100,00 & $100, \infty 0$ & 100,00 & 100,00 & 224,86 & 114,02 & 52,62 & 55,59 \\
\hline Curitiba & $P R$ & 17 & 1.893 .997 & 100,00 & 100,00 & 99,99 & 99,99 & 92,93 & 693,76 & 73,26 & 29,06 & 39,46 \\
\hline Campinas & SP & 18 & 1.173 .370 & 9785 & 99,60 & 90,87 & 92,46 & 67,98 & 551,41 & 93.99 & 12.56 & 21,59 \\
\hline Niterói & RJ & 19 & 497.883 & 100,00 & 100,00 & 94,78 & 94,78 & 100,00 & 158,77 & 63,78 & 20,03 & 33,10 \\
\hline Undial & $S P$ & 20 & 405.740 & 98,23 & 99,50 & 98,23 & 99,50 & 100,00 & 235,30 & 115,98 & 33,67 & 42,08 \\
\hline Indicador médio & & & $404.402^{1}$ & 99,34 & 99,93 & 95,99 & 98,27 & 89,17 & $171,93^{1}$ & $84,55^{2}$ & 24,62 & 32,97 \\
\hline
\end{tabular}

Fonte: Instituto Trata Brasil (2018).

Em se tratando de escala de estado, Niterói aparece em 1ำ colocado no Rio de Janeiro. Isso porque o município tem investido bastante na área de saneamento básico. Segundo o Grupo Águas do Brasil (2018) atualmente o município apresenta oito estações de tratamento de esgoto (ETEs) distribuídas por todo o território, e tem previsão de construir mais duas ETEs (Badu e Sapê), além da ampliação da ETE de Camboinhas, totalizando um investimento de $R \$ 120$ millhões para saneamento ambiental. No entanto, mesmo com estatísticas favoráveis, Niterói apresenta grandes desafios em relação ao esgotamento sanitário, conforme pode ser notado na figura 11.

Interessante notar na figura 11 que, enquanto em uma parte da bacia há setores censitários de 0 a 25\% de domicílios com esgotamento, como Engenho do Mato, no lado oposto há setores censitários com 90 a 100\%, nos bairros de Serra Grande e Maravista.

É importante que o poder público intensifique investimentos nos setores censitários que apresentaram as menores porcentagens de domicílios com esgotamento variando entre 0 e 25\%, principalmente no bairro do Engenho do Mato. A falta de rede e/ou de ligação de esgoto nessas áreas altera sensivelmente a vazão e a qualidade dos cursos d'água da região.

O Instituto Estadual do Ambiente (INEA) promove o monitoramento da qualidade das águas interiores no Estado do Rio de Janeiro por meio das estações de amostragem aplicando o Índice de Qualidade de Água (IQANSF). Este índice consolida em um único 
valor os resultados dos parâmetros: Oxigênio Dissolvido (OD), Demanda Bioquímica de Oxigênio (DBO), Fósforo Total (PT), Nitrogênio Nitrato (NO3), Potencial Hidrogeniônico $(\mathrm{pH})$, Turbidez (T), Sólidos Dissolvidos Totais (SDT), Temperatura da Água e do Ar e Coliformes Termotolerantes, conforme indica a figura 12. Periodicamente pelo site ou pela imprensa 0 (INEA) divulga os boletins sobre as condições dos corpos hídricos.

Figura 11 - Porcentagem de domicílios com esgotamento sanitário por setor censitário segundo dados do IBGE em 2010

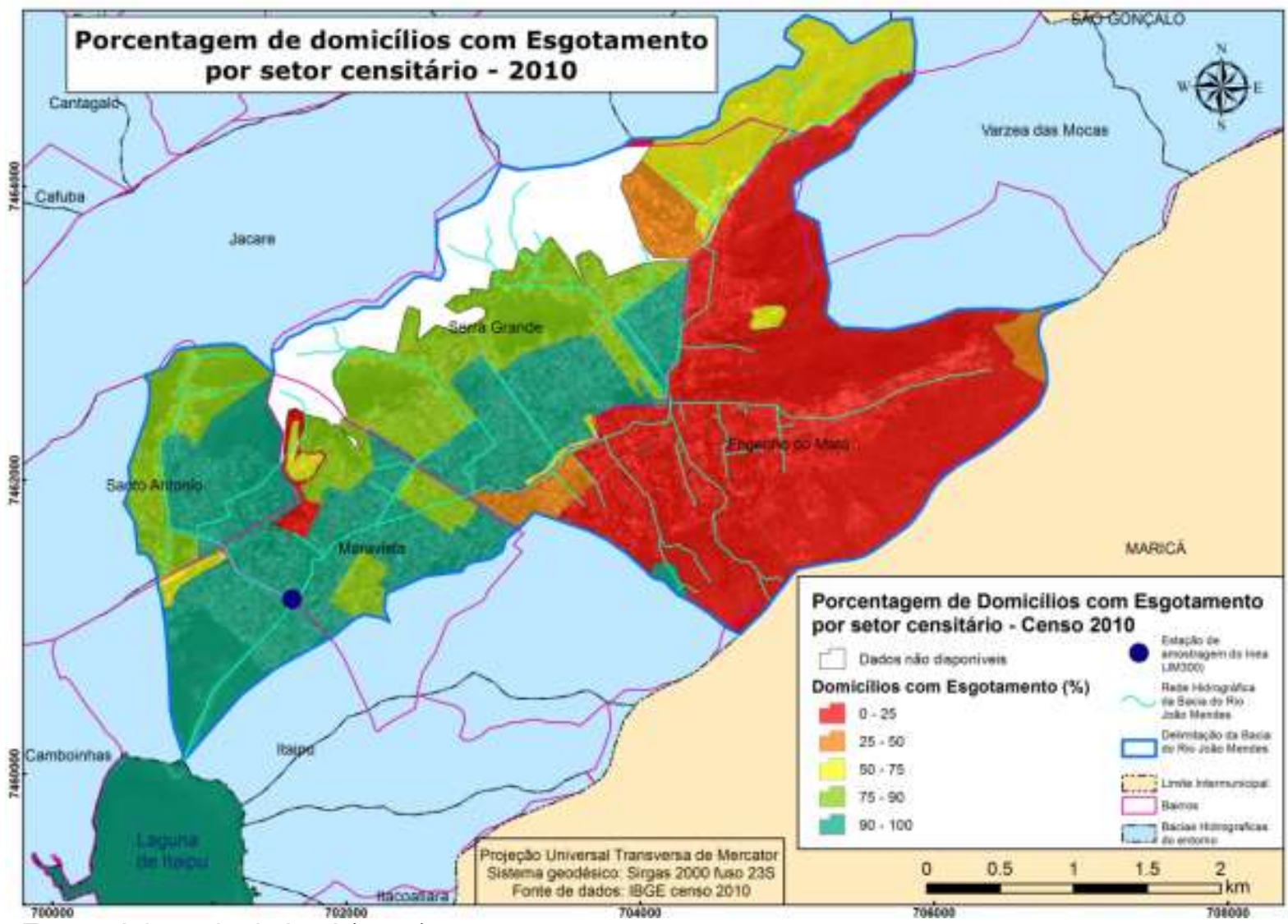

Fonte: Adaptado de Leal (2018).

Figura 12 - Boletim da qualidade das águas da Região Hidrográfica V - Baía de Guanabara- Bacia do Sistema Lagunar de Itaipu de 21 de maio de 2019

\begin{tabular}{|c|c|c|c|c|c|c|c|c|c|c|c|c|c|c|}
\hline$\frac{1}{8}$ & $\frac{5}{8}$ & $\frac{1}{1}$ & $\mathrm{E}$ & g & 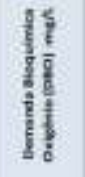 & $\frac{5}{\frac{5}{2}}$ & $\begin{array}{l}\frac{1}{2} \\
\frac{2}{2} \\
\frac{8}{2} \\
\frac{8}{2} \\
\frac{2}{2}\end{array}$ & 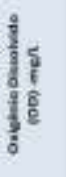 & $\frac{7}{2}$ & $\frac{5}{\frac{2}{2}}$ & $\frac{1}{3} \frac{1}{2}$ & 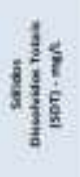 & $\frac{5}{4}$ & $\frac{2}{8}$ \\
\hline Naloo & BeAmeal & & 21/2/195 & 48 & $2 A$ & 60 & $2 \mu$ & 14 & 5,23 & 802 & 33000 & 312. & 13 & 30 \\
\hline $\mathrm{cm}$ & No arate & & $21 / 5 / 19$ & 2,2 & 12,0 & $2 \pi$ & 0,34 & 1,6 & 75 & 17,50 & 150000 & 128 & $x$ & 30 \\
\hline Mutio & misio Nendes & neero & $21 / 2 / 19$ & $\mathrm{nss}$ & c. 20 & $\Delta=1$ & a.s. & 10 & 734 & 858 & 502000 & $m$ & $n$ & $n$ \\
\hline $\operatorname{sen} 20$ & Sto Sunta Artiono & & 24/515 & 38,6 & 5,0 & 871 & 0,21 & 30 & 7,05 & 34,80 & 200000 & 333 & 23 & 31 \\
\hline \multicolumn{4}{|c|}{ 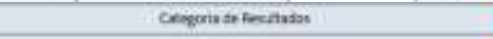 } & \multicolumn{2}{|c|}{ 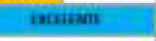 } & \multicolumn{2}{|c|}{$\min$} & \multicolumn{2}{|c|}{ stocin } & \multicolumn{2}{|c|}{$\sin$} & & & \\
\hline \multicolumn{4}{|c|}{ as } & \multicolumn{2}{|c|}{$100 \times n=4 \times 50$} & $\infty>0$ & & \multicolumn{2}{|c|}{ 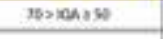 } & \multicolumn{2}{|c|}{ Nescapds } & \multicolumn{3}{|c|}{$x>n a s=0$} \\
\hline \multicolumn{4}{|c|}{ Merthate } & \multicolumn{6}{|c|}{ 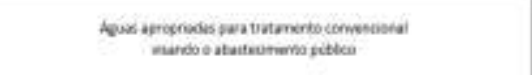 } & \multicolumn{5}{|c|}{ 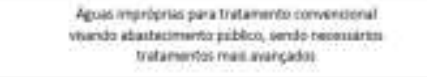 } \\
\hline
\end{tabular}

Fonte: Adaptado Instituto Estadual do Ambiente (2019). 
Assim, na figura 11 é representada a localização da estação de amostragem JM300 relacionada ao Rio João Mendes, próximo à foz e na figura 12 os resultados do monitoramento realizado no dia 21 de maio de 2019. É fatídico que a precariedade da disponibilidade de rede de esgoto ou de ligação à rede existente influencia o IQANSF, o qual apresenta o resultado de 35,9, sendo classificado como ruim.

Ressalta-se a quantidade de coliformes termortolerantes, relacionados a um grupo de bactérias que estão presentes em fezes, de $540.000 \mathrm{NMP} / 100 \mathrm{ml}$, um valor elevado tendo em vista que a resolução CONAMA no357 (BRASIL, 2005) estabelece $1.000 \mathrm{NMP} / 100 \mathrm{ml}$ para o contato primário. Essa aferição de maio da qualidade do Rio João Mendes demonstra o alto grau de degradação do corpo hídrico, nível crítico, devendo ser mais bem estudado no futuro, com amostras em diferentes períodos do dia, em diferentes profundidades ou com uma regularidade mensal para estabelecimento de média.

Aumentar a infraestrutura de drenagem e de esgotamento nessas áreas de grande vulnerabilidade promove não apenas uma melhor proteção ao ambiente ecologicamente equilibrado, mas tem impacto direto na saúde humana. Quando comparadas as figuras 3 e 4, nota-se que houve um crescimento urbano expressivo no bairro do Engenho do Mato no período de tempo analisado neste trabalho, e que a gestão e o planejamento urbano não se mostraram eficientes.

Assim sendo, boa parte da vazão do Rio João Mendes hoje é composta por água de esgoto, como pode ser observado na figura 13. Ainda nesta figura é possível perceber o assoreamento do rio a jusante.

Figura 13 - Esgoto no Rio João Mendes na Av. Irene Lopes Sodré, Engenho do Mato

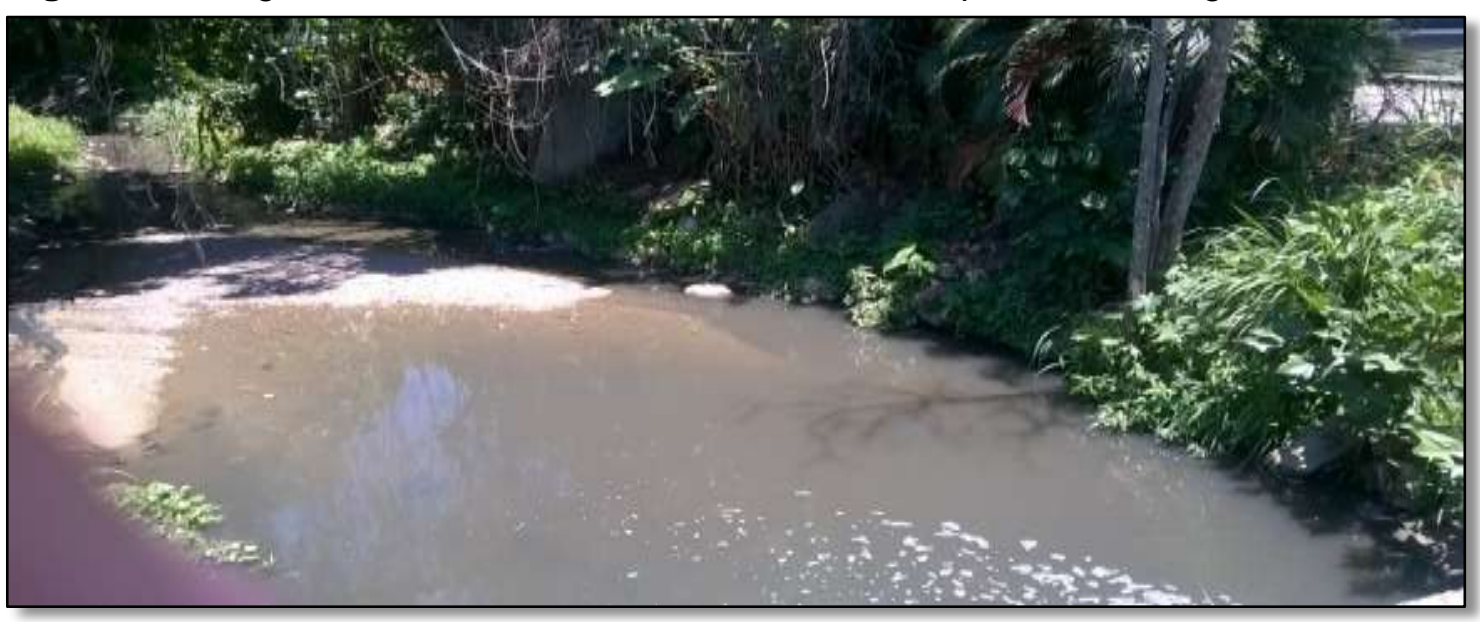

Fonte: Leal (2018). 
A ausência ou a presença diminuta de mata ciliar substituída por obras estruturais de concreto faz com que quase a totalidade dos materiais provenientes das erosões seja escoada superficialmente e direcionada para o curso d'água principal.

Cabe ressaltar, no que tange ao tratamento de ligação de residência à rede de esgoto, que há um esforço da Prefeitura juntamente com o Estado do Rio de Janeiro para estabelecer a ligação das residências em todo o município à rede de esgoto através do Projeto Se Liga. Segundo a Secretaria de Estado do Ambiente, órgão ligado ao governo do Estado do Rio de Janeiro, o objetivo deste projeto é diminuir o lançamento de efluentes sem tratamento na Baía de Guanabara e nas lagoas de Niterói, e o Projeto Se Liga apresenta resultados expressivos onde 862 imóveis do município de Niterói se conectaram à rede de esgotamento sanitário. Com isso, menos 336.180 litros de esgoto sem tratamento deixaram de ser despejado na baía e nessas lagoas por dia, o que configura uma boa prática de gestão que deve ser mantida e intensificada (RIO DE JANEIRO, 2018).

O Projeto Se Liga é fruto de um termo de cooperação técnica firmado entre a Concessionária Águas de Niterói e o (INEA). Desde então, a Concessionária repassa à Superintendência Regional Baía de Guanabara do (INEA) um levantamento prévio dos imóveis que não possuem conexão com a rede coletora. Posteriormente, os proprietários dos imóveis são notificados pelo (INEA) para se adequarem em até 60 dias, conforme preconiza o Decreto Estadual no 41.310 (RIO DE JANEIRO, 2008).

Assim cabe a intensificação das ações de fiscalização nos setores censitários com baixa porcentagem de esgotamento por município bem como a ampliação da rede de esgotamento sanitário.

\section{CONSIDERAÇÕES FINAIS}

Com os resultados obtidos foi possível identificar as áreas que apresentaram maior crescimento urbano entre 1976 e 2014 na bacia hidrográfica, bem como avaliar as áreas a partir da faixa de rendimentos em salários mínimos e da porcentagem de domicílios com esgotamento por setor censitário, que necessitam de ações prioritárias na bacia.

A metodologia proposta se mostrou eficiente e eficaz tendo em vista o objetivo do estudo, uma vez que foi possível tecer considerações relevantes para o subsídio do planejamento e gestão da bacia do Rio João Mendes. Destacam-se os trabalhos de campo na bacia e o uso do geoprocessamento que foram fundamentais para validação das informações aferidas.

Uma limitação encontrada está relacionada à análise da renda e da porcentagem de domicílios com esgotamento por setor censitário, pois os setores censitários são produto de uma média em uma determinada área, o que pode 
dificultar as análises das peculiaridades de cada setor pelo pesquisador. Com isso, para estudos futuros é importante a atenção especial às exceções que podem compor os setores censitários.

É salutar que haja políticas prioritárias pelo poder público tanto de instalação de rede de esgoto como ações de fiscalização para ligação das residências à mesma, principalmente nos setores censitários que apresentam entre 0 a $25 \%$ de casas ligadas à rede, os quais apresentam também os menores rendimentos por setor censitário.

\section{REFERÊNCIAS}

BRASIL. Presidência da República. Lei №12651 de 25 de maio de 2012. Dispõe sobre o novo código florestal brasileiro. Brasília, DF: Congresso Nacional, 2012. Disponível em: http://www.planalto.gov.br/ccivil_03/_Ato2011-2014/2012/Lei/L12651.htm. Acesso em: 20 maio 2019.

BRASIL. Ministério do Meio Ambiente. Conselho Nacional do Meio Ambiente. Resolução CONAMA № 357, de 17 de março de 2005. Brasília, DF: MMA, 2005. Dispõe sobre a classificação dos corpos de água e diretrizes ambientais para o seu enquadramento. Disponível em: http://www2. mma.gov.br/port/conama/legiabre.cfm?codlegi=459. Acesso em: 1 jul. 2019.

COELHO NETTO, A. L. Hidrologia de encosta na interface com a Geomorfologia. In: GUERRA, J. T., CUNHA, S. B. Geomorfologia: uma atualização de bases e conceitos. Rio de Janeiro: Bertrand Brasil, 2005. p. 93-148.

FREITAS, R. R. L. de. Mapeamento de risco a movimentos de massa e inundação em áreas urbanas do município de Moreno-PE. 2016. Dissertação (Mestrado em Engenharia Civil) - Departamento de Engenharia Civil, Universidade Federal de Pernambuco, Recife, 2016.

GALVÃO, R. S. Gestão de bacias hidrográficas em áreas urbanas. 2014. Tese (Doutorado em Geografia) - Universidade Federal Fluminense, Niterói, RJ, 2014.

GRUPO ÁGUAS DO BRASIL. Águas de Niterói. Estação de tratamento de esgoto.

Disponível em: https://www.grupoaguasdobrasil.com.br/aguas-niteroi/agua-eesgoto/estacao-tratamento-esgoto/. Acesso em: 15 nov. 2018.

GUERRA, A. J. T.; CUNHA, S. B. (org.). Geomorfologia: uma atualização de bases e conceitos. Rio de Janeiro: Bertrand Brasil, 1994.

IBGE. Censo demográfico 2010. Disponível em:

https://downloads.ibge.gov.br/downloads_estatisticas.htm. Acesso em: 1 dez. 2017.

INSTITUTO ESTADUAL DO AMBIENTE - INEA. Boletim de qualidade das águas da região hidrográfica V: Baía de Guanabara: bacia do sistema lagunar de Itaipu e Piratininga. Rio de Janeiro: INEA, 2019. (Boletim n. 2, p. 1-3, maio 2019). Disponível em:

http://www.inea.rj.gov.br/wp-content/uploads/2019/06/Boletim-IQA-RH-V-Bacia-do-SistemaLagunar-de-Itaipu-e-Piratininga-2019-N2.pdf. Acesso em: 4 jun. 2019.

INSTITUTO TRATA BRASIL. 20 melhores cidades do ranking do saneamento. São Paulo, SP: Trata Brasil, 2018. Estudos ITB, 24 abr. 2018. Disponível em:

http://www.tratabrasil.org.br/blog/2018/04/24/investimentos-das-100-maiores-cidades/. Acesso em: 14 maio 2018.

LEAL, T. S. Análise da suscetibilidade à inundação na bacia hidrográfica do Rio João Mendes, Niterói- RJ: planejamento e gestão das águas em áreas urbanas. 2018. 
Dissertação (Mestrado em Geografia) - Universidade do Estado do Rio de Janeiro, Rio de Janeiro, RJ, 2018.

LEAL, T. S.; ROCHA-LEÃO, O. M. Geotecnologias aplicadas na avaliação de conflitos ambientais nas áreas protegidas na bacia do rio João Mendes, Niterói - RJ. Revista Continentes, Seropédica, RJ, ano 1, n. 1, p. 20 - 33, 2018.

MAUS, V. W.; RIGHES, A. A.; BURIOL, G. A. Pavimento permeável e escoamento superficial da água em áreas urbanas. In: SIMPÓSIO DE RECURSOS HÍDRICOS DO NORTE E CENTRO-OESTE, 1., 2007, Cuiabá, MT. Anais [...] Cuiabá: ABRH, 2007. v. 1, p. 1-8.

NITERÓI. Prefeitura Municipal. Plano de drenagem da região oceânica. Niterói, RJ: Secretaria de Urbanismo, Meio Ambiente e Controle Urbano, 2002.

NITERÓI. Prefeitura Municipal. Secretaria Municipal de Conservação e Serviços Públicos SECONSER. Plano municipal de saneamento básico. Niterói, RJ: SECONSER, 2015. Disponível em: http://www.prosustentavel.niteroi.rj.gov.br/pdf/diagnostico_drenagem.pdf. Acesso em: 20 maio 2018.

RIO DE JANEIRO (Estado). Decreto no 41.310 de 15 de maio de 2008. Concede prazo para que condomínios e edificações no âmbito do estado do Rio de Janeiro se conectem a rede de esgoto. Rio de Janeiro, RJ: Governo do Estado, 2008. Disponível em:

https://futurelegis.com.br/legislacao/85451/Decreto-N\%C2\%BA-41310-de-15-05-2008.

Acesso em: 4 fev. 2019.

RIO DE JANEIRO. (Estado). Secretaria de Estado do Ambiente - SEA. Se liga Niterói. Rio de Janeiro, RJ: SEA, 2018. Disponível em:

http://www.rj.gov.br/web/sea/exibeconteudo?article-id=3906293. Acesso em: 14 maio 2018.

ROSA, R. Introdução ao sensoriamento remoto. Uberlândia, MG: EDUFU, 2009.

SAITO, S. M. Desastres naturais e geotecnologias: vulnerabilidade. São José dos Campos, SP: Instituto Nacional de Pesquisas Espaciais -INPE, 2011.

SECRETARIAT OF THE CONVENTION ON BIOLOGICAL DIVERSITY. Panorama da biodiversidade nas cidades. Montreal, QC: BiodivERsA, 2012.

VICHON, C.; TIBADUIZA, M.; CONTRERAS MOJICA, D.; KIENBERGER, S. Assessing vulnerability to natural hazards in Europe: from principles to practice. Orléans, UK: BRGM. Manual on methods and concepts. Disponível em: http://www.movefp7.eu/documents/MOVE_Manual.pdf. Acesso em: 25 nov. 2017.

Recebido: abril de 2019. Aceito: julho de 2019. 